\title{
A GENÈVE
}

\section{Décès de M. Charles Ammann, sous-directeur au CICR}

C'est avec un profond regret que le Comité international a appris la soudaine disparition de M. Charles Ammann. Entré au service de la Croix-Rouge en 1945 comme collaborateur de la Commission de gestion des secours en Grèce, il occupa successivement des postes où il eut l'occasion de témoigner de ses dons d'organisateur et de sa haute compétence dans le domaine de l'administration. Délégué-adjoint, puis chargé des problèmes de gestion à la délégation du CICR à Paris, il revint à Genève en 1951 pour prendre la direction du service des secours et, quelques années plus tard, de celui de la «Collecte».

En 1956, il assuma sous la responsabilité du commissaire général, M. Rutishauser, l'organisation pratique de la vaste action de secours entreprise par le CICR en faveur de la Hongrie et il était présent lorsque le premier convoi, parti de Vienne, pénétra, en novembre, en sol hongrois. Depuis lors, il accomplit des missions dans de nombreux pays, en particulier en Grèce et au Népal, puis, en 1960, au Congo. La même année, il était au Japon pour s'occuper du rapatriement des Coréens entrepris sous l'égide du CICR.

En 1967, il fut nommé sous-directeur et, en 1970, conseiller économique du Directeur du Département des Opérations. Comme tel, il assuma la responsabilité des relations du CICR avec la CEE. On sait l'ampleur de l'aide de cette institution à l'œuvre de la Croix-Rouge, et ce fait marque combien étaient importantes les négociations que M. Ammann mena à Bruxelles, tout récemment encore.

Ces quelques indications font voir l'utilité de la tâche poursuivie depuis de nombreuses années par M. Charles Ammann au service de la Croix-Rouge, et dans l'accomplissement de laquelle il témoigna de ses qualités d'énergie et d'abnégation. Le Comité international lui en demeure reconnaissant et il conservera de lui un fidèle souvenir. 